\title{
ePROs in the follow-up of cancer patients treated with immune checkpoint inhibitors: a retrospective study
}

\author{
Sanna livanainen ${ }^{1} \cdot$ Tuomo Alanko $^{2} \cdot$ Katriina Peltola $^{2} \cdot$ Teemu Konkola $^{3} \cdot$ Jussi Ekström $^{3} \cdot$ Henri Virtanen $^{3} \cdot$ \\ Jussi P. Koivunen ${ }^{1}$ (D)
}

Received: 19 November 2018 / Accepted: 24 December 2018 / Published online: 21 January 2019

(C) The Author(s) 2019

\begin{abstract}
Purpose Patient-reported outcome (PRO) follow-up has been shown to improve quality of life (QoL) and survival of cancer patients receiving chemotherapy. Kaiku Health application is a web-based electronic PRO (ePRO) tool which is designed for follow-up of cancer patients receiving immune checkpoint inhibitors (ICI). Purpose of the current study is to investigate whether symptoms collected by Kaiku Health ePRO tool on cancer patients receiving immune checkpoint inhibitors (ICI) follows to symptoms reported in clinical trials and whether coupling of specific symptoms does occur.

Methods We retrospectively collected data on symptom timing and severity, and QoL of patients followed with Kaiku Health IO module in two Finnish cancer centers between 2017 and 2018. Kaiku Health IO module consists of 18 adaptive questions, which assess the presence and severity of symptoms. Patients were requested (via e-mail) to fill online symptom questionnaires with 3-7 day interval and QoL questionnaires (QLQ-C30) with 1-2 month interval.

Results The IO module was used to follow 37 patients who had filled in total 559 symptom questionnaires. There was good adherence to ePRO follow-up with a median of 11 questionnaires filled per patient. The reported symptoms and their severity follow closely what has been seen in clinical trials investigating ICIs. Correlation analysis of the symptoms showed the strongest positive correlations between itching and rash; nausea and vomiting, decreased appetite, or stomach pain; cough and shortness of breath.

Conclusions The results of the current study suggest that real-world symptom data collected through the ePRO application on cancer patients receiving ICI therapy aligns with the data from clinical trials. Correlations between different symptoms occur, which might reflect therapeutic efficiency, side effects, or tumor progression. These correlations should be further investigated with data coupled to clinical outcomes.
\end{abstract}

Keywords Patient-reported outcomes $\cdot$ Immune checkpoint inhibitor therapy $\cdot$ Symptoms $\cdot$ Real-world data

Jussi P. Koivunen

jussi.koivunen@ppshp.fi

Sanna Iivanainen

sanna.iivanainen@ppshp.fi

Tuomo Alanko

tuomo.alanko@docrates.com

Katriina Peltola

katriina.peltola@docrates.com

Teemu Konkola

teemu.konkola@kaikuhealth.com
Jussi Ekström

jussi.ekstrom@kaikuhealth.com

Henri Virtanen

henri.virtanen@kaikuhealth.com

1 Department of Oncology and Radiotherapy, Oulu University Hospital (OYS), MRC Oulu, P.B. 22, 90029 Oulu, Finland

2 Docrates Cancer Center, Helsinki, Finland

3 Kaiku Health Oy, Helsinki, Finland 


\section{Introduction}

Cancer patients suffer from a variety of symptoms derived from the malignancy itself, whereas some arise as side effects of the given cancer treatments. Many symptoms are left unnoticed due to factors such as timely discontinuity between prescheduled health care appointments, individual disease history, and inadequate patient coherence (Reilly et al. 2013; Henry et al. 2008; Laugsand et al. 2010; Basch et al. 2009; Gilbert et al. 2012; Valderas et al. 2008; Velikova et al. 2010). In general, worsening of symptoms indicates cancer progression or severe side effects of the treatment and is linked to poorer cancer survival (Trajkovic-Vidakovic et al. 2012). Scheduled electronic patient-reported outcomes (ePROs) enable timely and continuous collection of symptoms in cost-effective manner (Jensen et al. 2014; Kotronoulas et al. 2014; Bennett et al. 2012; Cleeland et al. 2011; Holch et al. 2017; Mullen et al. 2004; Pakhomov et al. 2008). If ePROs are linked to an urgency algorithm, they offer a chance for prompt reaction to important medical events. Web-based applications coupled to urgency algorithm have been developed to monitor cancer patients, and currently, the most convincing data exist on patients receiving chemotherapy or undergoing follow-up for lung cancer (Basch et al. 2016; Denis et al. 2017). ePROs have been shown to improve quality of life (QoL), decrease emergency clinic visits, and improve Eastern Cooperative Oncology Group (ECOG) performance status and the number of patients receiving active cancer treatments at disease progression (Basch et al. 2016; Denis et al. 2017; Velikova et al. 2004). Furthermore, use of ePROs in patient monitoring has shown impressive improvements in overall survival compared to standard follow-up (Basch et al. 2017; Denis et al. 2017a, b). Increasing use of smartphones and apps in the general population supports the idea of collection of individual health data based on such communication channels (Benze et al. 2017). Nevertheless, web-based applications can be designed as scalable to take into account different user interfaces.

In the past 5 years, there has been a huge development in cancer immunotherapy with introduction of immune checkpoint inhibitor therapies such as PD-(L) 1 and CTLA-4 antibodies (Brahmer et al. 2015; Wolchok et al. 2017; Borghaei et al. 2015; Motzer et al. 2015; Bellmunt et al. 2017; Robert et al. 2015a, b; Herbst et al. 2016; Rittmeyer et al. 2017; Reck et al. 2016). The immune checkpoint inhibitors act through inhibition of T-cell blocking which results in T-cell-mediated cancer cell death. The side effects of immune checkpoint inhibitors resemble autoimmune disease. The most common ones are rash, endocrine toxicity, GI toxicity, hepatitis, and pneumonitis.
Even life-threatening side effects can occur, but they can, in most cases, be managed with early detection, delaying or stopping of the immuno-oncological (IO) therapy and initiation of immunosuppressive medication, most commonly corticosteroids (Spain et al. 2016; Puzanov et al. 2017; Haanen et al. 2017; Wang et al. 2018). Timing of side effects differs from traditional cancer therapy and they can occur from months to years after therapy initiation or after discontinuation of the therapy (Li et al. 2017; McDermott et al. 2015; Weber et al. 2017). Therefore, long-term follow-up of patients even after therapy discontinuation is warranted.

There are no published works investigating ePRO follow-up approach on cancer patients treated with ICIs. Current study investigates symptoms collected by ePRO tool on cancer patients receiving ICIs and their correlation to data presented on clinical trials and coupling of the reported symptoms. The study hypothesis are that ePRO collection of symptoms would be similar or higher compared to clinical trials and certain symptoms co-occur.

\section{Methods}

\section{Patients}

All the study patients included had cancer being treated with IO therapy at Docrates Cancer Center (Helsinki, Finland) and Oulu University Hospital (Oulu, Finland) in outpatient setting 4/2017-9/2018 and they were followed with Kaiku ePRO module and had at least one symptom questionnaire filled. Data on symptom and QoL questionnaires were retrospectively collected from data registry of Kaiku Health at 9/2018 of all the patients filling the inclusion criteria. Of the clinical variables, the registry included only age and sex of the patients but no additional clinical variables. Data collection was done under permits from Kaiku Health, Docrates Cancer Center, and Oulu University Hospital Ethics Committee $(9 / 2017)$.

\section{ePRO follow-up}

Kaiku Health ePRO tool is a web-based solution scaled to be used fluently in smartphones and home computers. Kaiku Health IO module developed by Kaiku Health consists of 18 questions. The symptoms selected for the Kaiku Health symptom-tracking tool for cancer immunotherapy are based on the most common adverse events that have occurred during clinical trials of anti-PD-1, anti-PD-L1, and anti-CTLA4 monotherapies. The symptoms tracked by the instrument are potential signs and symptoms of immune-related adverse events. The symptom selection is based on the reported publications of following clinical trials: CheckMate 017, 
CheckMate 026, CheckMate 057, CheckMate 066, CheckMate 067, KEYNOTE-010, and OAK. FDA labels for Nivolumab, Pembrolizumab, and Atezolizumab were also used in the symptom selection for the instrument. The questions for each symptom in the instrument were developed based on NCI-CTCAE v.4.03 register by converting the description of gradings into a patient-friendly language. Any criteria that are impossible for patients to report have been excluded from the available questions. Developing the symptom questionnaire in this manner has enabled the selfreporting of patients and development of an algorithm that provides an assessment and an approximation of the severity of each symptom.

Questions asses the presence of blood in stool, blood in urine, blurred vision, chest pain, cough, decreased appetite, diarrhea, dizziness, fatique, fever, headache, itching, nausea, other symptoms, pain in joints, rash, shortness of breath, stomach pain, and vomiting. Besides recording a presence of a symptom, the application has a severity algorithm that grades the symptom according to NCI-CTAE v. 4.03 protocol. Furthermore, the application has a feature of an urgency algorithm that sends out alerts to the care unit when the patient reports predefined severe or altering symptoms (limits set by care unit). This feature could be activated by the care unit, but this was used only in part of the study patients and the data on alerts was excluded from the analysis. QoL was captured with electronic QLQ-C30-questionnaire included in the Kaiku ePRO module.

\section{Results}

\section{Patient cohort and engagement to ePRO follow-up}

A total of 37 patients with median age of 61 were included in the study. 24 (64.9\%) of the patients were male. The subjects filled 559 questionnaires focusing on known immunologically related adverse events (irAEs) and 133 QoL

A

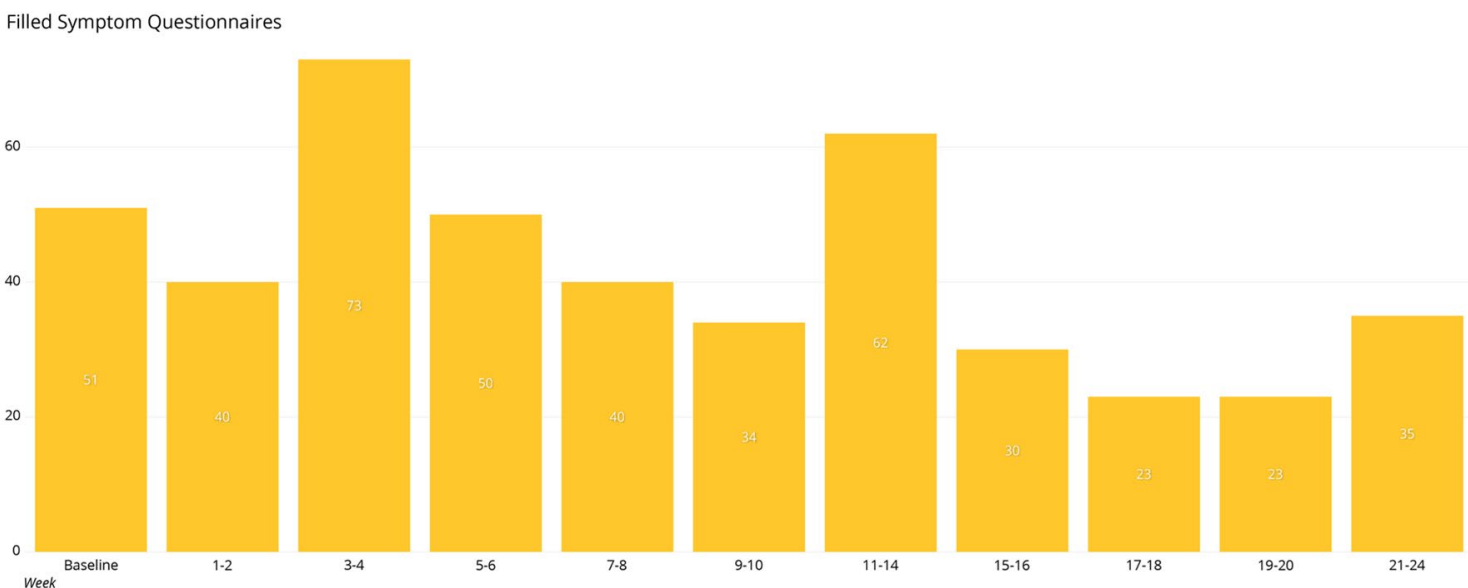

\section{B}

Filled Quality of Life Questionnaires
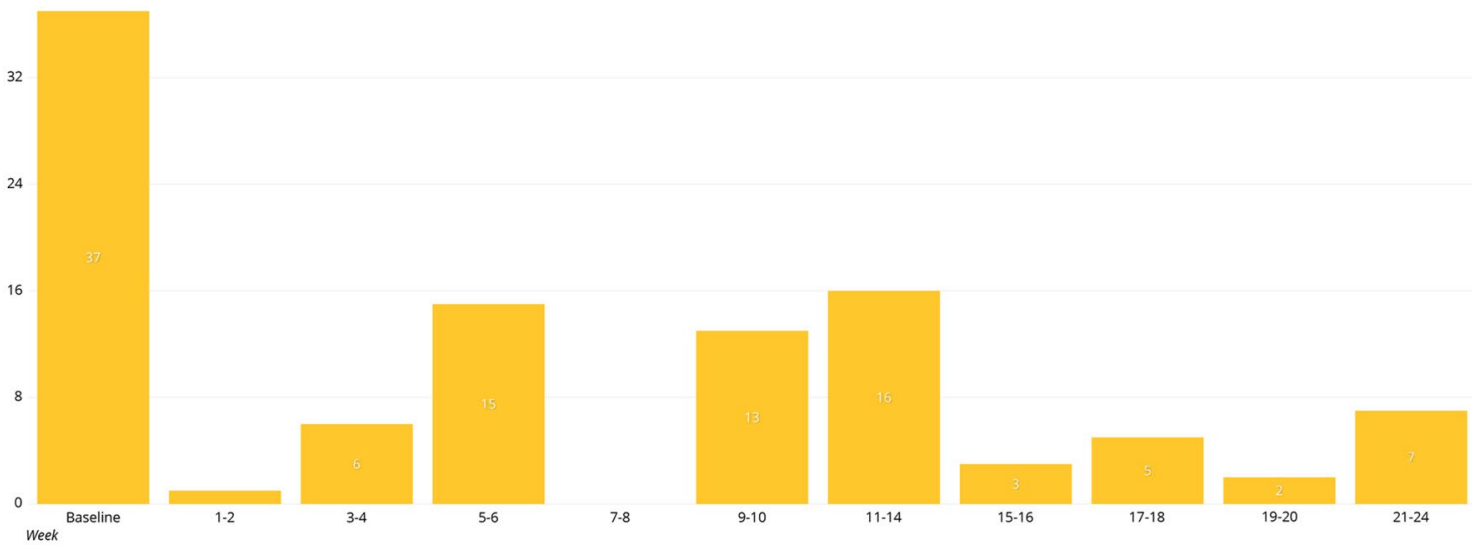

Fig. 1 Number of filled questionnaires in timely relation to the baseline a symptom questionnaires, $\mathbf{b}$ quality-of-life questionnaires 
questionnaires. There was good compliance to ePRO surveillance up to 24 weeks from baseline. The answering rate to symptom questionnaires was highest at 3-4 weeks (the number of symptom questionnaires filled $n=73$ ), 11-14 weeks ( $n=62)$, and baseline $(n=51)$ (Fig. 1a). The median number of filled symptom questionnaires was 11 per patient (CI 1-47; SD 12.3). All the patients included had initial QoL questionnaires filled, but the answering rate was much lower at later time points analyzed (Fig. 1b). Median number of filled QoL questionnaires was two (CI 1-18; SD 3.47), and the answering rate was highest at 11-14 weeks.

At the time of analysis, most patients $(n=28)$ had $>12$ weeks from the first filled symptom questionnaire and 19 of $28(67.9 \%)$ patients had continued the symptom reporting for $>12$ weeks, suggesting good adherence to ePRO follow-up. Of the 28 patients, one (3.6\%) had the highest reported symptoms at severity grade 0 , seven $(25 \%)$ at grade 2 , and 20 patients $(71.4 \%)$ at grade $\geq 3$. According to reported symptom severity, patients with grade 0 had on average 0.1 questionnaires filled per week, grade 2 patients 0.65 questionnaires/week, and grade $\geq 3$ patients 0.66 questionnaires/week.

\section{Symptoms and QoL during ePRO follow-up}

Email remainders to patients of symptom questionnaires to be filled were sent out initially and, thereafter, at 3-7 day frequency. The reported symptoms were categorized by severity algorithm of the application (grade 0-4) and grouped to timely to baseline, 12 and 24 weeks. Symptoms and their grading in all the filled questionnaires are presented in Table 1. The most common reported grade 1-2 symptoms were fatigue (47\%), shortness of breath (31\%), and cough (29\%). Of the grade 3-4 symptoms, decreased appetite (5\%), other symptoms (5\%), and chest pain (3\%) were the most frequent. The development of symptoms and their severity from baseline to 12 and 24 weeks is presented in Fig. 2. Since urgency algorithm was activated only on some of patients, data on the urgency algorithm alerts was excluded from the current analysis.

Email remainders to patients of QoL questionnaires to be filled were sent out initially and, thereafter, at 1-2 months frequency. QLQ-C30 scales are presented in Fig. 3. In general, there was tendency for improvement in all the scales from baseline to 12 and 24 weeks.

\section{Symptom and QoL correlations}

Correlations of different patient-reported symptoms were analyzed using heat maps. The strongest positive correlations were seen between itching and rash, and between
Table 1 Distribution of severity of the reported symptoms according to all the answered $(\mathrm{n}=559)$ symptom questionnaires

\begin{tabular}{llll}
\hline Symptom & Grade $0(\%)$ & $\begin{array}{l}\text { Grades } 1-2 \\
(\%)\end{array}$ & $\begin{array}{l}\text { Grades } \\
3-4 \\
(\%)\end{array}$ \\
\hline Blood in stool & 100 & 0 & 0 \\
Blood in urine & 99 & 1 & 1 \\
Blurred vision & 98 & 1 & 0 \\
Chest pain & 92 & 6 & 3 \\
Cough & 69 & 29 & 2 \\
Decreased appetite & 82 & 13 & 5 \\
Diarrhea & 95 & 5 & 1 \\
Dizziness & 93 & 6 & 1 \\
Fatique & 50 & 47 & 3 \\
Fever & 96 & 4 & 0 \\
Headache & 93 & 7 & 0 \\
Itching & 86 & 12 & 2 \\
Nausea & 84 & 15 & 1 \\
Other symptoms & 71 & 24 & 5 \\
Pain in joints & 85 & 13 & 2 \\
Rash & 87 & 13 & 1 \\
Shortness of breath & 67 & 31 & 2 \\
Stomach pain & 90 & 9 & 1 \\
Vomiting & 97 & 3 & 0 \\
\hline
\end{tabular}

nausea and vomiting. Furthermore, positive correlations were seen between nausea, decreased appetite, and stomach pain; and cough and shortness of breath. Analyzes did not show high level of negative correlations between individual symptoms. Interestingly, however, negative correlations were seen between certain groups of symptoms. Rash, itching, joint pain, and diarrhea negatively correlated with cough, shortness of breath, and chest pain (Fig. 4a).

The same method was also applied to correlation analysis between QoL scales (QLQ-C30) and patient-reported symptoms. According to the results, of the reported symptoms, lower QoL scale and lower global health status had strongest correlation with fatigue, decreased appetite, nausea, and dizziness (Fig. 4b).

\section{Discussion}

The toxicity spectrum of immune checkpoint inhibitor therapies is wide and inadequately characterized (Le Burel et al. 2017; Pillai et al. 2018). Timing of AEs with traditional chemotherapies and targeted therapies is strongly connected to the initiation of the medication, while irAEs typically occur later in the treatment course or even after discontinuing the therapy. Furthermore, even though some irAEs are more common than others, the spectrum of potential AEs 

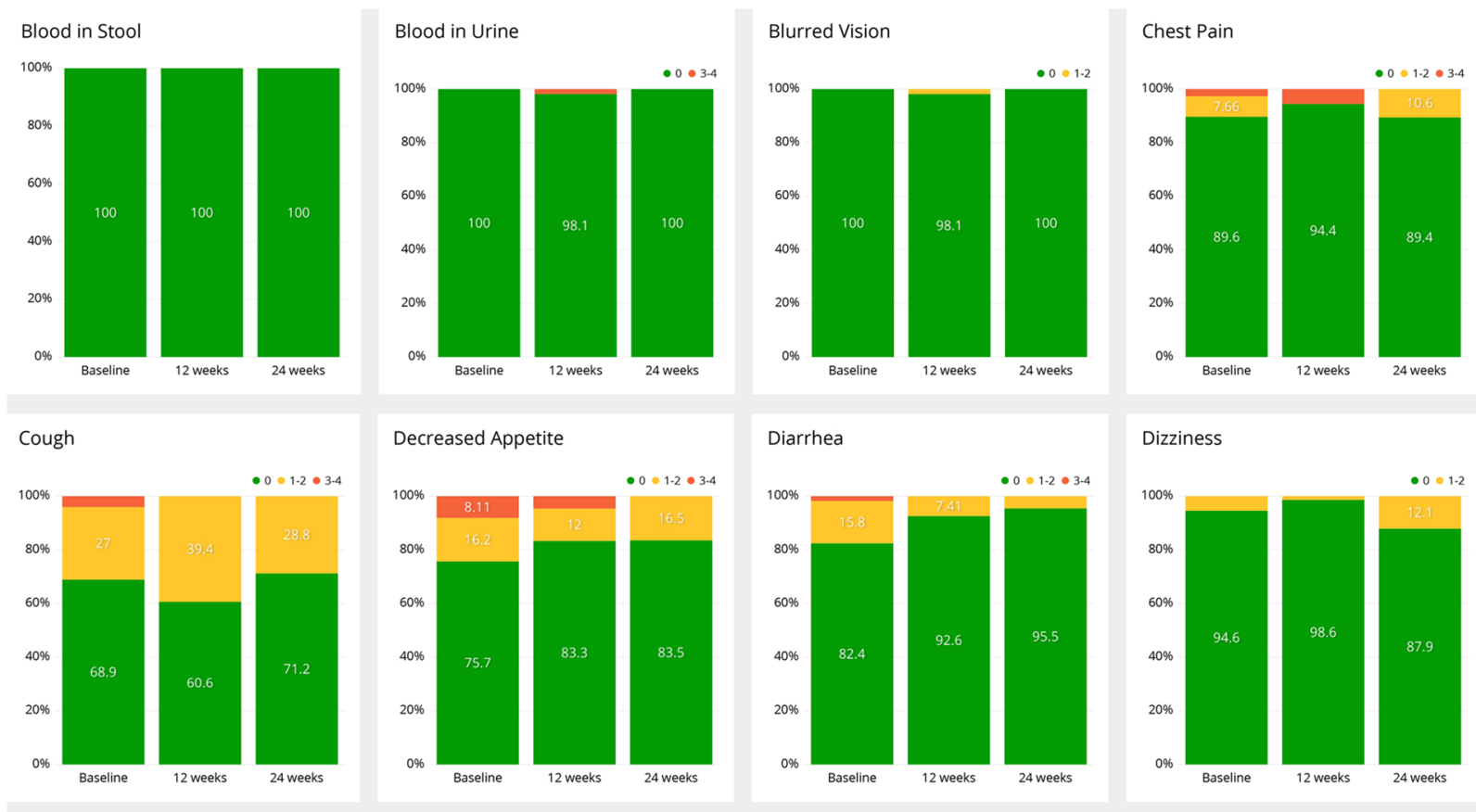

\section{Dizziness}
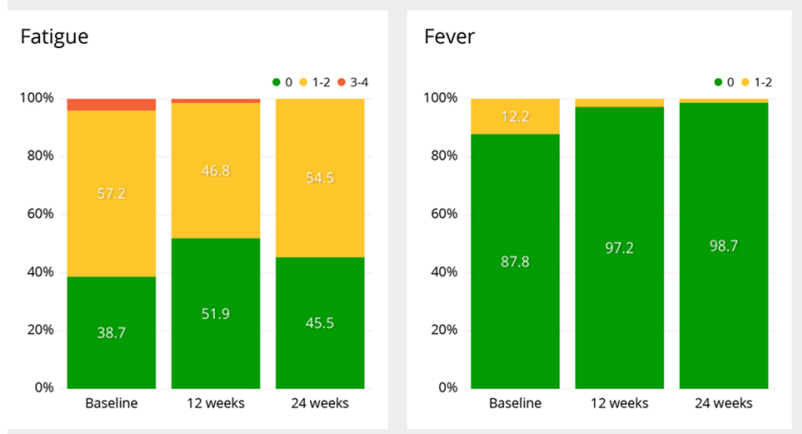

\section{Headache}
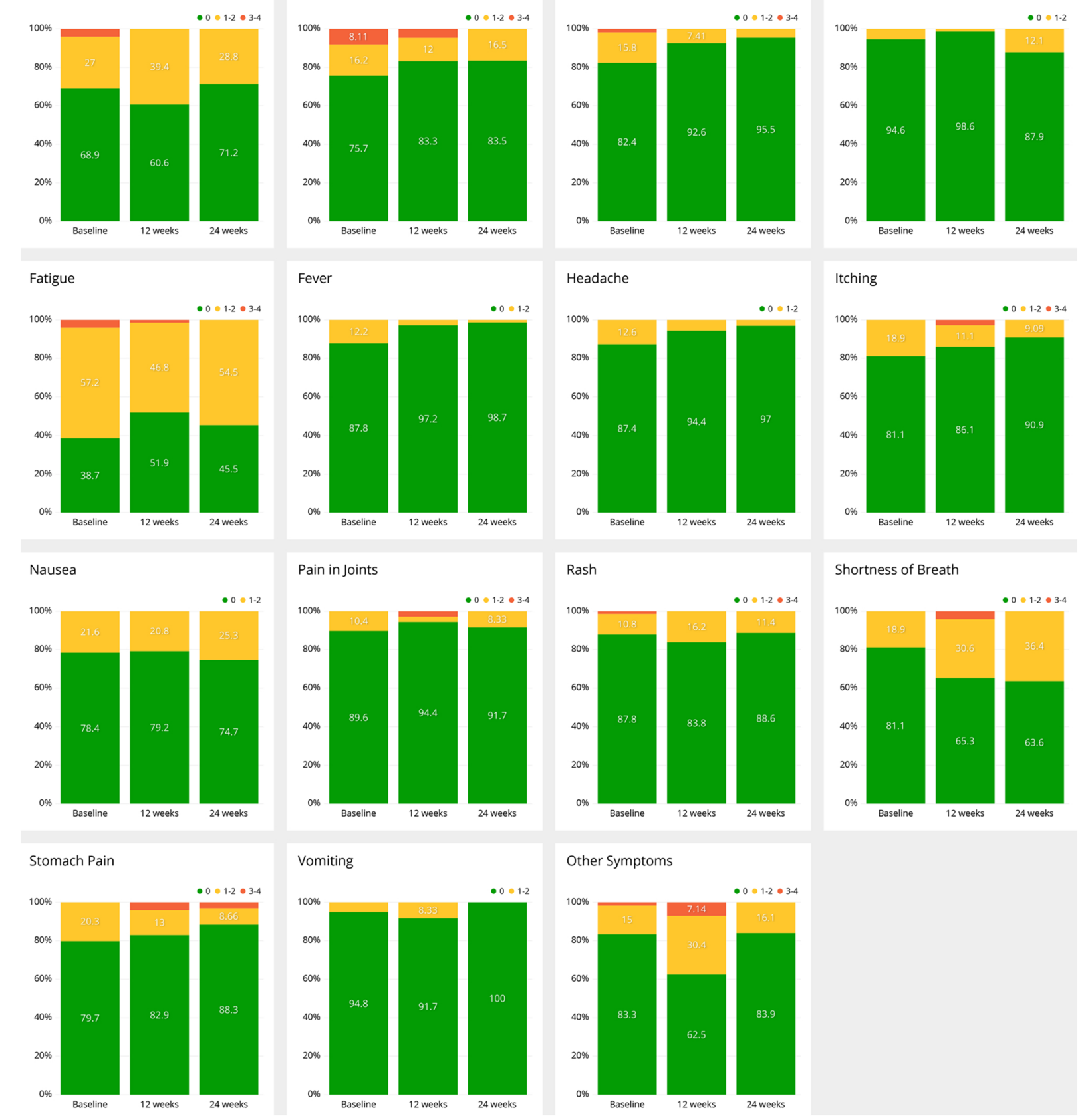

Shortness of Breath
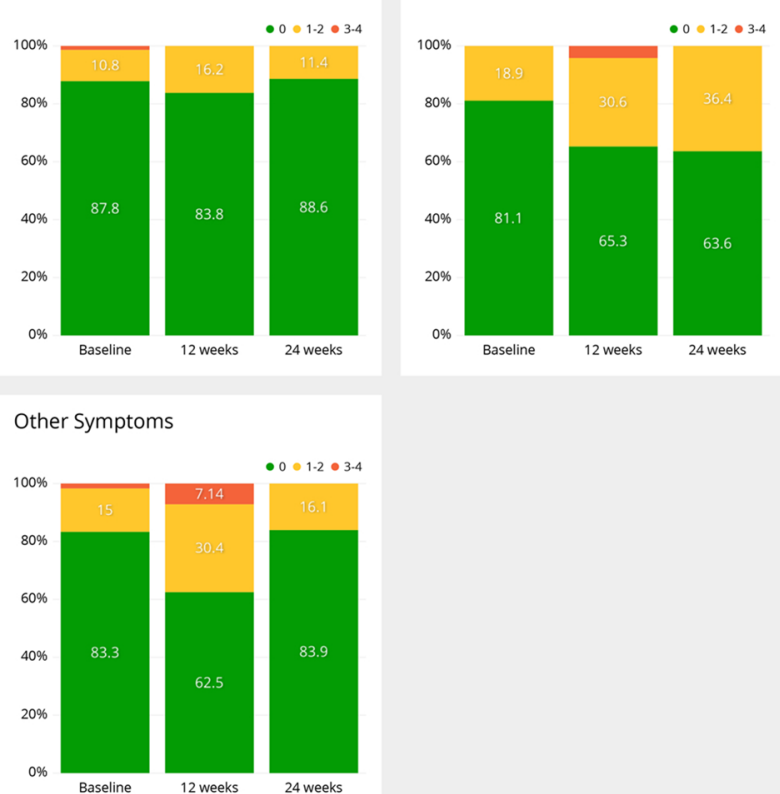

Fig. 2 Development of specific symptoms at baseline, 12 and 24 weeks according to NCI-CTCAE grading $(0,1-2,3-4)$ Grade 0 is marked with green, grade 1-2 yellow, and grade 3-4 red 
is wider compared to traditional cancer medications. Early detection of irAEs is suggested to improve their management and decrease the need for hospitalization (Champiat et al. 2016; Michot et al. 2016). To our knowledge, the current study is the first investigating ePROs in the follow-up of cancer patients receiving immune checkpoint inhibitor therapies. Our study provides evidence that this approach is feasible based on the good patient adherence and strong correlation of $\mathrm{AE}$ spectrum to the previous clinical trials.

The answering rate to QoL questionnaires was much lower (median 2) compared to symptom reporting rate. This is probably due to the lower frequency of QoL-questionnaire scheduling (every 1-2 months) compared to symptom questionnaires (every 3 days to weekly). Furthermore, compliance to QoL questionnaires might be lower because of the more complicated nature of the questionnaires making them less appealing to the patient.

Patient-reported real-world data (RWD) on immune checkpoint inhibitor related side effects is limited. The variety and severity of patient-reported symptoms in our study seem to follow closely to what has been seen in the clinical trials investigating ICIs (Brahmer et al. 2015; Robert et al. 2015; Wolchok et al. 2017; Borghaei et al. 2015; Herbst et al. 2016; Rittmeyer et al. 2017; Reck et al. 2016; Schachter et al. 2017). For example, respiratory events like cough and dyspnea have been documented in up to $20-40 \%$ of patients receiving anti-PD-(L)1-therapies with grade 3-4 cough in 2-9\% (Haanen et al. 2017) which is closely
Fig. 4 Correlation analysis using heat maps a correlation between reported symptoms, b correlation between symptoms and QoL by QLQ-C30 global health status and functioning scales The intensity of the color signifies the level of correlation; red negative, blue positive correlation. Strong correlation ratio is defined $>0.5$ or $<-0.5$; intermediate $0.5-0.3$ or -0.5 to -0.3 ; weak $0.3-0.1$ or -0.3 to -0.1 ; very weak 0.1 to -0.1

congruent with our data $(29 / 31 \%$ and $2 / 2 \%)$. Furthermore, frequencies of arthralgia and rash (both 13\%) are very similar to clinical studies (both 15\%) (Michot et al. 2016; SuarezAlmazor et al. 2017).

The symptom correlation analysis revealed coupling of certain symptoms with positive and negative correlations. Strong positive correlations were seen between predicted irAEs like rash and itching, and on the other hand, pulmonary symptoms (cough and shortness of breath). Interestingly, rash, itching and joint pain, typical irAEs, had negative correlations with cough, shortness of breath and chest pain which often are related to disease progression in the context of lung cancer or lung metastases (Haanen 2017). Our finding of negative correlation between well-known irAEs and disease progression-related symptoms supports the hypothesis that incidence of irAEs with ICI therapies is suggestive of potential clinical benefit to the patient (Fujii et al. 2018). Data of the current study did not include clinical outcomes excluding age and sex, and therefore, symptom correlations are hypothesis generating only. This should be

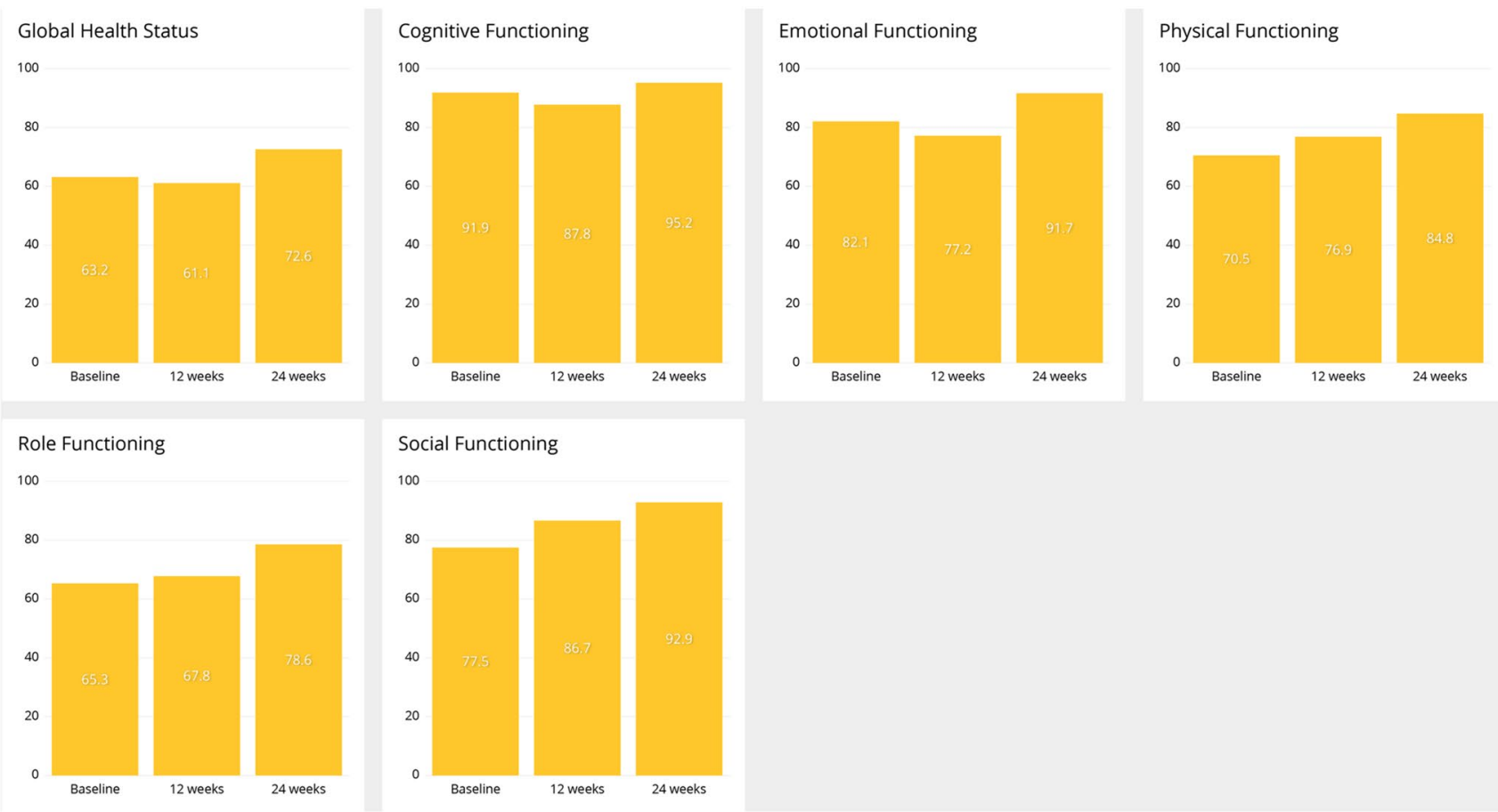

Fig. 3 Development of QoL according QLQ-C30 global health status and functioning scales at baseline, 12 and 24 weeks 
A

B

B
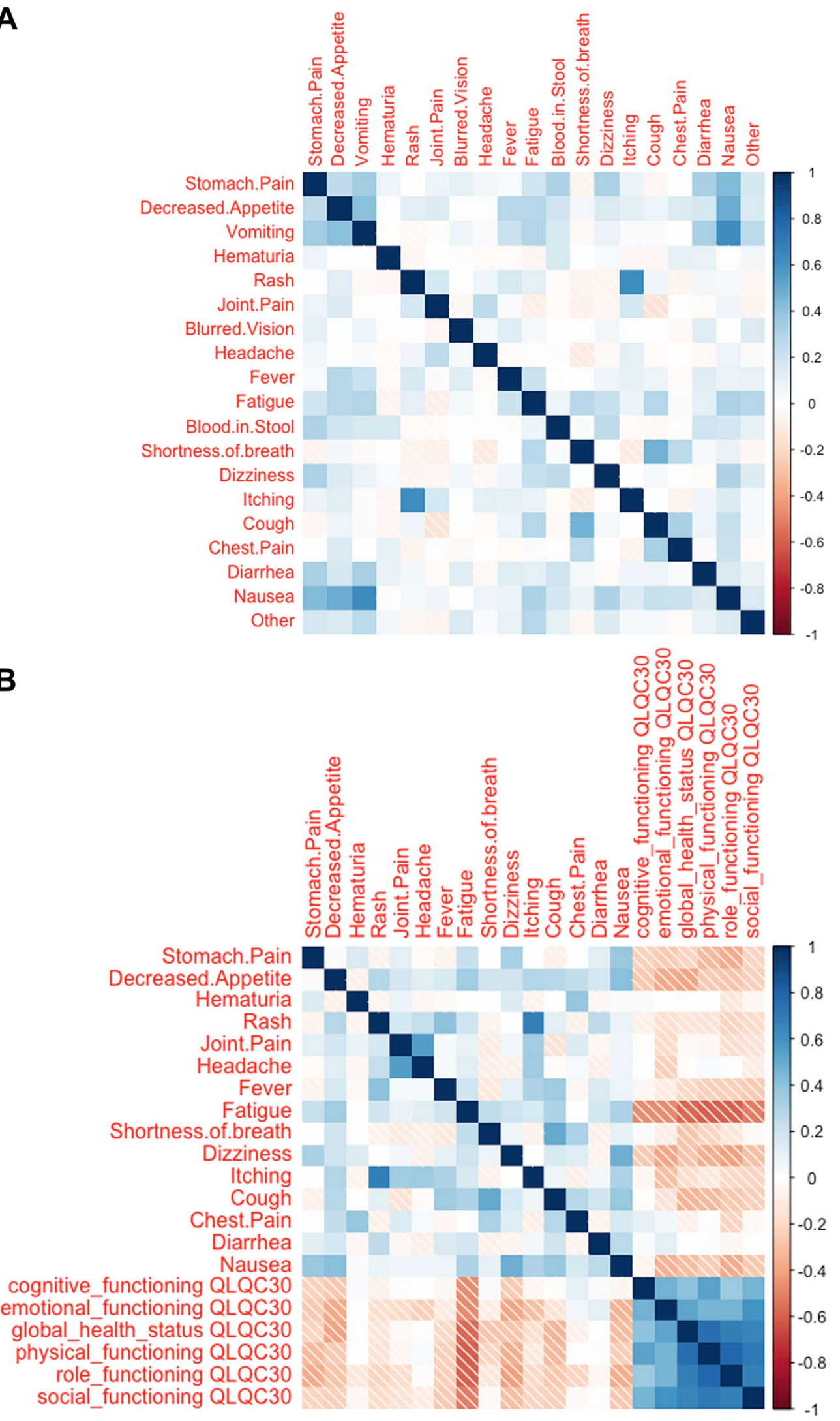
further investigated with comprehensive, prospective study linking symptoms to clinical outcomes.

The correlation of patient-reported symptoms to QoL (global health status and functioning scales) showed in general highly negative correlations excluding joint pain, headache, shortness of breath, chest pain and diarrhea. This suggests that clinical decision-making aiming to improve patients' well-being based on merely QoL-reporting is difficult. Our findings support the idea that the clinical value of follow-up of cancer patients is increased when individualized symptom analysis is combined to standard measurements (Velikova et al. 2008) .

In summary, our results show that ePRO follow-up of cancer patients treated with immune checkpoint inhibitors is feasible. The symptom variety, incidence, and grading collected with ePRO questionnaire from real-world patients mimics what has been reported in anti-PD-(L)1trials making our results clinically convincing. The correlation analysis showed a negative correlation between common irAEs and symptoms suggesting disease progression which should be further investigated with data linked to clinical outcomes.

Acknowledgements Open access funding provided by University of Oulu including Oulu University Hospital.

Author contributions SI and JPK contributed to the conception and design of the study; SI, JPK, TA, KP, HV, TK, and JE acquired the data; TK and JE analyzed the data and SI and JPK interpreted the data. SI and JPK contributed to the writing of the manuscript. All authors read and approved the final manuscript.

Funding Study was funded by Oulu University. Kaiku Health employees were involved in the data acquiring and analysis.

\section{Compliance with ethical standards}

Conflict of interest SI and KP declare that they have no competing interests. TK, JE, and HV are employees of Kaiku Health, and HV owns stock in Kaiku Health. JPK and TA are advisors for Kaiku Health.

Ethics approval and consent to participate According to national legislation, informed consent is not needed due to the retrospective and non-interventional nature of the study.

Availability of data and materials The data sets generated and/or analyzed during the current study are not publicly available but are available from the corresponding author on reasonable request.

OpenAccess This article is distributed under the terms of the Creative Commons Attribution 4.0 International License (http://creativeco mmons.org/licenses/by/4.0/), which permits unrestricted use, distribution, and reproduction in any medium, provided you give appropriate credit to the original author(s) and the source, provide a link to the Creative Commons license, and indicate if changes were made.

\section{References}

Basch E, Jia X, Heller G, Barz A, Sit L, Fruscione M et al (2009) Adverse symptom event reporting by patients vs clinicians: relationships with clinical outcomes. J Natl Cancer Inst 101(23):1624-1632. https://doi.org/10.1093/jnci/djp386

Basch E, Deal AM, Kris MG, Scher HI, Hudis CA, Sabbatini P et al (2016) Symptom monitoring with patient-reported outcomes during routine cancer treatment: a randomized controlled trial. J Clin Oncol 34(6):557-565. https://doi.org/10.1200/JCO.2015.63.0830

Basch E, Deal AM, Dueck AC, Scher HI, Kris MG, Hudis C et al (2017) Overall survival results of a trial assessing patientreported outcomes for symptom monitoring during routine cancer treatment. JAMA 318(2):197-198. https://doi.org/10.1001/ jama.2017.7156

Bellmunt J, de Wit R, Vaughn DJ, Fradet Y, Lee JL, Fong L et al (2017) Pembrolizumab as second-line therapy for advanced urothelial carcinoma. N Engl J Med 376(11):1015-1026. https://doi. org/10.1056/NEJMoa1613683

Bennett AV, Jensen RE, Basch E (2012) Electronic patient-reported outcome systems in oncology clinical practice. CA Cancer J Clin 62(5):337-347. https://doi.org/10.3322/caac.21150

Benze G, Nauck F, Alt-Epping B, Gianni G, Bauknecht T, Ettl J, Munte A, Kretzschmar L, Gaertner J (2017) PROutine: a feasibility study assessing surveillance of electronic patient reported outcomes and adherence via smartphone app in advanced cancer. Ann Palliat Med. https://doi.org/10.21037/apm.2017.07.05

Borghaei H, Paz-Ares L, Horn L, Spigel DR, Steins M, Ready NE et al (2015) Nivolumab versus docetaxel in advanced nonsquamous non-small-cell lung cancer. N Engl J Med 373(17):1627-1639. https://doi.org/10.1056/NEJMoa1507643

Brahmer JR, Rodriguez-Abreu D, Robinson AG, Hui R, Csoszi T, Fulop A et al (2017) Health-related quality-of-life results for pembrolizumab versus chemotherapy in advanced, PD-L1-positive NSCLC (KEYNOTE-024): a multicentre, international, randomised, openlabel phase 3 trial. Lancet Oncol 18(12):1600-1609

Champiat S, Lambotte O, Barreau E, Belkhir R, Berdelou A, Carbonnel F et al (2016) Management of immune checkpoint blockade dysimmune toxicities: a collaborative position paper. Ann Oncol 27(4):559-574. https://doi.org/10.1093/annonc/mdv623

Cleeland CS, Wang XS, Shi Q, Mendoza TR, Wright SL, Berry MD et al (2011) Automated symptom alerts reduce postoperative symptom severity after cancer surgery: a randomized controlled clinical trial. J Clin Oncol 29(8):994-1000. https://doi. org/10.1200/JCO.2010.29.8315

Denis F, Yossi S, Septans AL, Charron A, Voog E, Dupuis O et al (2017a) Improving survival in patients treated for a lung cancer using self-evaluated symptoms reported through a web application. Am J Clin Oncol 40(5):464-469. https://doi.org/10.1097/ COC. 0000000000000189

Denis F, Lethrosne C, Pourel N, Molinier O, Pointreau Y, Domont J et al (2017b) Randomized trial comparing a web-mediated followup with routine surveillance in lung cancer patients. J Natl Cancer Inst 109(9):https://doi.org/10.1093/jnci/djx029

Fujii T, Colen RR, Bilen MA, Hess KR, Hajjar J, Suarez-Almazor $\mathrm{ME}$ et al (2018) Incidence of immune-related adverse events and its association with treatment outcomes: the MD anderson cancer center experience. Investig New Drugs 36(4):638-646. https://doi.org/10.1007/s10637-017-0534-0

Gilbert JE, Howell D, King S, Sawka C, Hughes E, Angus H et al (2012) Quality improvement in cancer symptom assessment and control: the provincial palliative care integration project (PPCIP). J Pain Symptom Manag 43(4):663-678. https://doi. org/10.1016/j.jpainsymman.2011.04.028 
Haanen JBAG, Carbonnel F, Robert C, Kerr KM, Peters S, Larkin $\mathrm{J}$ et al (2018) Management of toxicities from immunotherapy: ESMO clinical practice guidelines for diagnosis, treatment and follow-up. Ann Oncol. https://doi.org/10.1093/annonc/mdy162

Henry DH, Viswanathan HN, Elkin EP, Traina S, Wade S, Cella D (2008) Symptoms and treatment burden associated with cancer treatment: results from a cross-sectional national survey in the U.S. Support Care Cancer 16(7):791-801. https://doi. org/10.1007/s00520-007-0380-2

Herbst RS, Baas P, Kim DW, Felip E, Perez-Gracia JL, Han JY et al (2016) Pembrolizumab versus docetaxel for previously treated, PD-L1-positive, advanced non-small-cell lung cancer (KEYNOTE-010): a randomised controlled trial. Lancet 387(10027):1540-1550. https://doi.org/10.1016/S0140 $-6736(15) 01281-7$

Holch P, Warrington L, Bamforth LCA, Keding A, Ziegler LE, Absolom K et al (2017) Development of an integrated electronic platform for patient self-report and management of adverse events during cancer treatment. Ann Oncol 28(9):2305-2311. https:// doi.org/10.1093/annonc/mdx317

Jensen RE, Snyder CF, Abernethy AP, Basch E, Potosky AL, Roberts AC et al (2014) Review of electronic patient-reported outcomes systems used in cancer clinical care. J Oncol Pract 10(4):e215e222. https://doi.org/10.1200/JOP.2013.001067

Kotronoulas G, Kearney N, Maguire R, Harrow A, Di Domenico $\mathrm{D}$, Croy S et al (2014) What is the value of the routine use of patient-reported outcome measures toward improvement of patient outcomes, processes of care, and health service outcomes in cancer care? A systematic review of controlled trials. J Clin Oncol 32(14):1480-1501. https://doi.org/10.1200/ JCO.2013.53.5948

Laugsand EA, Sprangers MA, Bjordal K, Skorpen F, Kaasa S, Klepstad P (2010) Health care providers underestimate symptom intensities of cancer patients: a multicenter european study. Health Qual Life Outcomes 8:104-7525. https://doi.org/10.1186/1477-7525-8-104

Le Burel S, Champiat S, Mateus C, Marabelle A, Michot JM, Robert $C$ et al (2017) Prevalence of immune-related systemic adverse events in patients treated with anti-programmed cell death 1/antiprogrammed cell death-ligand 1 agents: a single-centre pharmacovigilance database analysis. Eur J Cancer 82:34-44

Li H, Ma W, Yoneda KY, Moore EH, Zhang Y, Pu LL et al (2017) Severe nivolumab-induced pneumonitis preceding durable clinical remission in a patient with refractory, metastatic lung squamous cell cancer: a case report. J Hematol Oncol 10(1):64-017. https:// doi.org/10.1186/s13045-017-0433-z

McDermott DF, Drake CG, Sznol M, Choueiri TK, Powderly JD, Smith DC et al (2015) Survival, durable response, and long-term safety in patients with previously treated advanced renal cell carcinoma receiving nivolumab. J Clin Oncol 33(18):2013-2020. https://doi. org/10.1200/JCO.2014.58.1041

Michot JM, Bigenwald C, Champiat S, Collins M, Carbonnel F, PostelVinay $S$ et al (2016) Immune-related adverse events with immune checkpoint blockade: a comprehensive review. Eur J Cancer 54:139-148

Motzer RJ, Escudier B, McDermott DF, George S, Hammers HJ, Srinivas $S$ et al (2015) Nivolumab versus everolimus in advanced renal-cell carcinoma. N Engl J Med 373(19):1803-1813. https:// doi.org/10.1056/NEJMoa1510665

Mullen KH, Berry DL, Zierler BK (2004) Computerized symptom and quality-of-life assessment for patients with cancer part II: acceptability and usability. Oncol Nurs Forum 31(5):E84-E89. https:// doi.org/10.1188/04.ONF.E84-E89

Pakhomov SV, Jacobsen SJ, Chute CG, Roger VL (2008) Agreement between patient-reported symptoms and their documentation in the medical record. Am J Manag Care 14(8):530-539
Pillai RN, Behera M, Owonikoko TK, Kamphorst AO, Pakkala S, Belani CP et al (2018) Comparison of the toxicity profile of PD-1 versus PD-L1 inhibitors in non-small cell lung cancer: a systematic analysis of the literature. Cancer 124(2):271-277. https://doi. org/10.1002/cncr.31043

Puzanov I, Diab A, Abdallah K, Bingham CO 3rd, Brogdon C, Dadu R et al (2017) Managing toxicities associated with immune checkpoint inhibitors: consensus recommendations from the society for immunotherapy of cancer (SITC) toxicity management working group. J Immunother Cancer 5(1):95-017. https://doi.org/10.1186/ s40425-017-0300-z

Reck M, Rodriguez-Abreu D, Robinson AG, Hui R, Csoszi T, Fulop A et al (2016) Pembrolizumab versus chemotherapy for PD-L1-positive non-small-cell lung cancer. N Engl J Med 375(19):18231833. https://doi.org/10.1056/NEJMoa1606774

Reilly CM, Bruner DW, Mitchell SA, Minasian LM, Basch E, Dueck AC et al (2013) A literature synthesis of symptom prevalence and severity in persons receiving active cancer treatment. Support Care Cancer 21(6):1525-1550. https://doi.org/10.1007/s0052 0-012-1688-0

Rittmeyer A, Barlesi F, Waterkamp D, Park K, Ciardiello F, von Pawel $\mathrm{J}$ et al (2017) Atezolizumab versus docetaxel in patients with previously treated non-small-cell lung cancer (OAK): a phase 3 , open-label, multicentre randomised controlled trial. Lancet 389(10066):255-265

Robert C, Schachter J, Long GV, Arance A, Grob JJ, Mortier L et al (2015a) Pembrolizumab versus ipilimumab in advanced melanoma. N Engl J Med 372(26):2521-2532. https://doi.org/10.1056/ NEJMoa1503093

Robert C, Long GV, Brady B, Dutriaux C, Maio M, Mortier L et al (2015b) Nivolumab in previously untreated melanoma without BRAF mutation. N Engl J Med 372(4):320-330. https://doi. org/10.1056/NEJMoa1412082

Schachter J, Ribas A, Long GV, Arance A, Grob JJ, Mortier L et al (2017) Pembrolizumab versus ipilimumab for advanced melanoma: final overall survival results of a multicentre, randomised, open-label phase 3 study (KEYNOTE-006). Lancet 390(10105):1853-1862

Spain L, Diem S, Larkin J (2016) Management of toxicities of immune checkpoint inhibitors. Cancer Treat Rev 44:51-60. https://doi. org/10.1016/j.ctrv.2016.02.001

Suarez-Almazor ME, Kim ST, Abdel-Wahab N, Diab A (2017) Review: immune-related adverse events with use of checkpoint inhibitors for immunotherapy of cancer. Arthritis Rheumatol 69(4):687-699. https://doi.org/10.1002/art.40043

Trajkovic-Vidakovic M, de Graeff A, Voest EE, Teunissen SC (2012) Symptoms tell it all: a systematic review of the value of symptom assessment to predict survival in advanced cancer patients. Crit Rev Oncol Hematol 84(1):130-148. https://doi.org/10.1016/j.critr evonc.2012.02.011

Valderas JM, Kotzeva A, Espallargues M, Guyatt G, Ferrans CE, Halyard MY et al (2008) The impact of measuring patient-reported outcomes in clinical practice: a systematic review of the literature. Qual Life Res 17(2):179-193. https://doi.org/10.1007/s1113 6-007-9295-0

Velikova G, Booth L, Smith AB, Brown PM, Lynch P, Brown JM et al (2004) Measuring quality of life in routine oncology practice improves communication and patient well-being: a randomized controlled trial. J Clin Oncol 22(4):714-724. https://doi. org/10.1200/JCO.2004.06.078

Velikova G, Awad N, Coles-Gale R, Wright EP, Brown JM, Selby PJ (2008) The clinical value of quality of life assessment in oncology practice-a qualitative study of patient and physician views. Psychooncology 17(7):690-698. https://doi.org/10.1002/pon.1295

Velikova G, Keding A, Harley C, Cocks K, Booth L, Smith AB et al (2010) Patients report improvements in continuity of care when 
quality of life assessments are used routinely in oncology practice: secondary outcomes of a randomised controlled trial. Eur J Cancer 46(13):2381-2388. https://doi.org/10.1016/j.ejca.2010.04.030

Wang DY, Salem JE, Cohen JV, Chandra S, Menzer C, Ye F et al (2018) Fatal toxic effects associated with immune checkpoint inhibitors: a systematic review and meta-analysis. JAMA Oncol. https://doi.org/10.1001/jamaoncol.2018.3923

Weber JS, Hodi FS, Wolchok JD, Topalian SL, Schadendorf D, Larkin $\mathrm{J}$ et al (2017) Safety profile of nivolumab monotherapy: a pooled analysis of patients with advanced melanoma. J Clin Oncol 35(7):785-792. https://doi.org/10.1200/JCO.2015.66.1389

Wolchok JD, Chiarion-Sileni V, Gonzalez R, Rutkowski P, Grob JJ, Cowey CL et al (2017) Overall survival with combined nivolumab and ipilimumab in advanced melanoma. N Engl J Med 377(14):1345-1356. https://doi.org/10.1056/NEJMoa1709684 